\title{
Fontes de Lactose, Níveis de Lisina Dietéticos e Peso dos Leitões ao Desmame ${ }^{1}$ \\ Eurípedes Laurindo Lopes², Otto Mack Junqueira³, Lúcio Francelino Araújo4, Romão da Cunha Nunes $^{2}$, Karina Ferreira Duarte ${ }^{5}$
}

\begin{abstract}
RESUMO - Desenvolveu-se um experimento com o objetivo de avaliar o uso de fontes de lactose (soro de leite em pó e lactose) e níveis de lisina em rações (1,20 e 1,50\%), além do peso ao desmame ( $\leq 6,0$ e >6,0 kg), sobre o desempenho e a morfologia intestinal de 384 leitões desmamados com diferentes pesos e idade de 21 dias. Os leitões foram distribuídos em delineamento inteiramente casualizado em esquema fatorial $2 \times 2 \times 2$, totalizando oito tratamentos em quatro repetições cada. Três leitões de cada tratamento foram abatidos aos 42 dias de idade, quando foram coletadas amostras do duodeno para estudo da morfologia intestinal. Foram avaliadas as características de desempenho ganho de peso, consumo de ração e conversão alimentar. Altura das vilosidades, profundidade de criptas duodenais e a relação altura de vilosidades/profundidade de criptas, bem como a relação peso do pâncreas/peso da carcaça, foram as características morfológicas avaliadas. O uso de lactose em rações à base de milho e farelo de soja proporcionou melhor desempenho dos leitões quando combinado a um nível de $1,5 \%$ de lisina. Concluiu-se ainda que os tipos de dietas estudados não exerceram efeito sobre a morfologia do duodeno e a relação peso do pâncreas/peso corporal e que a altura das vilosidades é uma função direta do peso do leitão.
\end{abstract}

Palavras-chave: lactose, leitões, lisina, soro de leite em pó

\section{Lactose Sources and Lysine Levels in Diets for Weaning Piglets}

ABSTRACT - One experiment was carried out to evaluate the use of lactose sources (dried whey and lactose) and lysine levels (1.20 and $1.50 \%$ ) in diets for weaned piglets with diferent body weight at 21 days of age, regarding performance and intestinal morphology of piglets in initial phase. Three hundred and eighty-four piglets from 21 to 42 days were sorted in a complete randomized design with a 2 x 2 x 2 factorial arrangement, in a total of eight treatments and four replications each. Samples of duodenum from three piglets slaughtered at 42 days of age were harvested from each treatment to study intestinal morphology. The following performance characteristics were evaluated: weight gain, feed intake and feed conversion. The morphologycal parameters were as follows: villous height, duodenum crypt depth, villous height/duodenum crypt depth ratio and pancreas/carcass weight ratio. Performance of piglets fed corn-soybean meal- based diets with lactose was better when the level of lysine was of $1.5 \%$. It was also concluded that the type of diets studied did not alter the morphologycal parameters and that the villous height is a direct function of piglet weight.

Key Words: dried whey, lactose, lysine, piglets

\section{Introdução}

Atualmente, existe tendência de diminuição da idade e do desmame com vistas a maior número de leitões terminados por porca/ano. Uma vez que o desmame aos 21 dias de idade tem mostrado resultados bastante variáveis, alternativas para alimentação dos leitões nesta fase têm sido objeto de muitas pesquisas.

Partridge (1988) observou que a taxa de crescimento de leitões após o desmame, com 5 a 7 kg de peso, é limitada pela baixa ingestão de ração e que dietas com altos níveis de farelo de soja levam ao desenvolvimento de reações de hipersensibilidade e, conseqüentemente, à ocorrência de diarréias nesta fase. Assim, a necessi- dade de aumentar a ingestão de ração, sem predispor o leitão a problemas digestivos, implica a utilização de dietas com alta digestibilidade e utilização dos nutrientes da ração (Walker et al., 1986).

Danielson et al. (1960), em estudos sobre o efeito de combinações de leite desnatado seco e soro de leite seco no ganho de peso e na eficiência alimentar de leitões desmamados com idade média de 16 dias, observaram que, durante 28 dias pós-desmame, uma dieta com $30 \%$ de leite desnatado e $10 \%$ de soro seco proporcionou maior ganho de peso. Verificaram, ainda, que o ganho e a eficiência alimentar reduziram quando o nível de soro seco na dieta foi superior a $10 \%$.

\footnotetext{
${ }^{1}$ Parte da tese de Doutorado do primeiro autor. FAPESP Proc. 98/7374-6.

2 Docente Departamento de Produção Animal EV/UFG - E.mail: ellopes@vet.ufg.br

3 Docente Departamento de Zootecnia FCAVJ/UNESP - E.mail: ottomack@fcav.unesp.br

${ }^{4}$ Docente Departamento de Zootecnia FZEA/USP - Avenida Duque de Caxias Norte, 225. CP - 23. CEP 13635-900 Pirassununga/SP.

E.mail: Ifaraujo@usp.br

${ }^{5}$ Médica Veterinária, Pós-graduação em Zootecnia da FCAVJ/UNESP.
} 
Ao substituirem a proteína do leite pela proteína da soja para leitões desmamados aos 21 dias de idade, Walker et al. (1986) constataram menor velocidade de crescimento e pior eficiência alimentar dos animais nas duas primeiras semanas pós-desmame; entretanto, após esse período, as duas fontes protéicas proporcionaram resultados semelhantes. As diferenças foram atribuídas à maior disponibilidade de aminoácidos no leite.

Em trabalho com leitões desmamados aos 21 dias de idade, Tokach et al. (1990) observaram maior ganho de peso diário durante a fase inicial nos leitões que receberam ração contendo leite em pó e soro de leite que naqueles alimentados com ração simples à base de milho e farelo de soja.

Mahan \& Lepine (1991) verificaram que leitões com idade de 21 a 28 dias, desmamados com baixo peso (4,1 a 5,0 kg), responderam melhor às rações complexas contendo farelo de soja e soro de leite seco com suplementação de aminoácidos e dextrose que os alimentados com ração simples. Os autores sugeriram que ração destinada a leitões mais pesados por ocasião do desmame $(7,3$ a $8,6 \mathrm{~kg})$ pode conter menor concentração de produtos lácteos.

Comparando dietas à base de milho e farelo de soja para leitões desmamados aos 23 dias de idade, com ou sem suplementação de soro de leite em pó e níveis de lisina variando de 1,1 a 1,5\%, Lepine et al. (1991) observaram maior ganho de peso nos primeiros 21 dias após o desmame nos animais que receberam ração contendo $25 \%$ de soro de leite, independentemente do nível de lisina. Resultados semelhantes foram encontrados por Mahan et al. (1993), quando incluíram 20\% de soro de leite em pó e níveis de lisina de 0,95 ou $1,1 \%$ na dieta. Esses autores sugeriram a possibilidade de a lactose ser o dissacarídeo mais limitante em dietas à base de milho e farelo de soja.

Existem variações nos níveis de lisina recomendados para leitões. Donzele et al. (1992) mencionam o nível de 1,18\% de lisina para leitões entre 5 e 15 kg de peso, ao passo que Rostagno et al. (1994) citam o valor de 1,043\% para a mesma fase. O NRC (1998) recomenda utilizar $1,35 \%$ de lisina nas rações para leitões de 5 a 10 kg e 1,15\% para animais de 10 a 20 kg. Baker (1998), por sua vez, em experimentos desenvolvidos na Universidade de Illinois, sugeriu um esquema de alimentação dividido em três etapas, compreendendo os períodos de 0 a 7, 7 a 14 e 14 a 21 dias após o desmame, e recomendou níveis de 1,5; 1,4 e $1,15 \%$ de lisina, respectivamente.
Durante o desmame, a composição da dieta dos leitões muda drasticamente, uma vez que o leite da porca é substituído por uma dieta com maior nível de matéria seca, composta por carboidratos como as principais fontes de energia, com a substituição da lactose pelo amido (Spreeuwenberg et al., 2003). Desse modo, a transição do desmame é acompanhada por um período de baixa ingestão de alimentos que resulta em redução da altura das vilosidades (Puskle et al., 1996; Verdonk et al., 2001). Vale assinalar que a integridade do trato gastrointestinal é fundamental para os processos de digestão e absorção dos nutrientes dietéticos, pois, em leitões, o período pósdesmame é caracterizado por perda de peso e, em determinadas situações, pela ocorrência de diarréia de origem bacteriana ou nutricional. Nota-se que, no intestino, os resíduos alimentares não digeridos servem como substratos para fermentação, por ação da microflora intestinal, e conseqüente produção de ácido láctico e ácidos graxos voláteis. Juntamente com os resíduos alimentares restantes e os minerais, esses ácidos aumentam a osmolaridade do conteúdo intestinal, dificultando o processo de reabsorção de água e resultando em um afluxo elevado de líquido para a luz intestinal, o que desencadeia diarréia (Etheridge et al., 1984).

O pâncreas é um dos órgãos de maior importância nos processos digestivos, como demonstrado por Pekas et al. (1964), em estudo sobre os efeitos da obstrução do ducto pancreático sobre a digestibilidade das proteínas da soja e do leite pelos leitões com duas a oito semanas de idade. Esses autores verificaram que a digestibilidade da proteína e da matéria seca foi reduzida, sobretudo para os leitões alimentados com dietas contendo proteínas de soja. Passillé et al. (1989) alertam para a necessidade de o pâncreas apresentar adequado desenvolvimento por ocasião do desmame dos leitões, uma vez que suas enzimas têm papel importante na digestão de dietas que contêm amido e proteínas vegetais.

Segundo Kenworthy (1976), há relatos de alterações na estrutura do intestino delgado após o desmame como fatores predisponentes de baixos desempenhos de leitões nesta fase. Vale ressaltar que o sistema imunodigestivo é um importante mecanismo controlador dos problemas entéricos, protegendo o epitélio intestinal da ação de microrganismos patogênicos e de fatores antigênicos de origem alimentar (Nabuurs, 1995). 
De acordo com Kenworthy (1976), alterações da morfologia intestinal de leitões decorrem de uma reação inflamatória aguda causada por metabólitos derivados da degradação microbiana dos alimentos. Nesse sentido, convém destacar relato de Miller et al. (1984) de que o trato digestivo apresenta uma resposta imune transitória aos antígenos presentes nos alimentos. Antes do desenvolvimento da tolerância imunológica a esses antígenos, o sistema imunodigestivo pode passar por um período de hipersensibilidade, dado importante no caso de leitões desmamados em idade antecipada. O desenvolvimento desse sistema é influenciado pela quantidade e qualidade do alimento consumido antes do desmame (Miller et al., 1986), diminuindo as atividades enzimáticas da membrana da borda em escova dos enterócitos localizados no intestino delgado dos leitões (Hampson \& Kidder, 1986).

Em trabalho com leitões desmamados aos 21 dias de idade, Dunsford et al. (1989) observaram que ração à base de milho e farelo de soja induziu o aparecimento de vilosidades deformadas e maior espessura da lâmina própria. Esses autores concluíram que a inclusão de altas concentrações de farelo de soja (32 ou 44\%) na ração inicial de leitões acentua os efeitos prejudiciais do desmame efetuado em idade antecipada sobre o intestino delgado.

Neste trabalho, avaliou-se o efeito de duas fontes de lactose (soro de leite em pó e lactose) e de dois níveis de lisina sobre o desempenho, o peso do pâncreas e as características morfológicas do trato intestinal de leitões desmamados com diferentes pesos.

\section{Material e Métodos}

Utilizaram-se 384 leitões, distribuídos em 32 baias compostas por 12 animais (seis machos e seis fêmeas) por unidade experimental. O experimento foi analisado segundo delineamento experimental inteiramente casualizado, em um arranjo fatorial $2 \times 2 \times 2$. Os fatores estudados foram fontes de lactose (soro de leite em pó ou lactose), níveis de lisina (1,20 e 1,50\%) e peso dos leitões ao desmame ( $\leq 6,0$ e $>6,0 \mathrm{~kg})$, totalizando oito tratamentos com quatro repetições cada um. O período de avaliação foi dos 21 aos 42 dias de idade.

Todas as rações, à base de milho e farelo de soja, foram formuladas para conterem a mesma porcentagem de lactose $(8,64 \%)$, proveniente do soro de leite em pó ou da lactose (Tabela 1$)$. A ração foi fornecida quatro vezes ao dia, em quantidade calculada para não
Tabela 1 - Composição percentual das dietas experimentais

Table 1 - Composition (\%) of experimental diets

\begin{tabular}{|c|c|c|}
\hline $\begin{array}{l}\text { Ingrediente (\%) } \\
\text { Ingredient }\end{array}$ & $\begin{array}{l}\text { Soro de leite em pó } \\
\text { Dried whey }\end{array}$ & $\begin{array}{l}\text { Lactose } \\
\text { Lactose }\end{array}$ \\
\hline $\begin{array}{l}\text { Milho moído } \\
\text { Ground corn }\end{array}$ & 54,67 & 54,14 \\
\hline $\begin{array}{l}\text { Farelo de soja } \\
\text { Soybean meal }\end{array}$ & 29,80 & 33,00 \\
\hline $\begin{array}{l}\text { Soro de leite em pó } \\
\text { Dried whey }\end{array}$ & 12,00 & - \\
\hline $\begin{array}{l}\text { Lactose } \\
\text { Lactose }\end{array}$ & - & 8,64 \\
\hline $\begin{array}{l}\text { Supl. vitamínico-mineral } \\
\text { Vitamin and mineral mix }\end{array}$ & 0,40 & 0,40 \\
\hline $\begin{array}{l}\text { Sal comum } \\
\text { Salt }\end{array}$ & 0,35 & 0,58 \\
\hline $\begin{array}{l}\text { Fosfato bicálcico } \\
\text { Dicalcium phosphate }\end{array}$ & 1,30 & 1,60 \\
\hline $\begin{array}{l}\text { Calcário calcítico } \\
\text { Limestone }\end{array}$ & 0,70 & 0,80 \\
\hline $\begin{array}{l}\text { DL-metionina } \\
\text { DL-methionine }\end{array}$ & 0,08 & 0,14 \\
\hline $\begin{array}{l}\text { Óxido de zinco } \\
\text { Zinc oxide }\end{array}$ & 0,40 & 0,40 \\
\hline $\begin{array}{l}\text { Porção variável } \\
\text { Variable portion }\end{array}$ & 0,30 & 0,30 \\
\hline
\end{tabular}

Níveis nutricionais

Nutritional levels

\begin{tabular}{|c|c|c|}
\hline Proteína bruta (\%) & 20,00 & 20,00 \\
\hline \multicolumn{3}{|l|}{ Crude protein } \\
\hline Energia digestível (kcal/kg) & 3317 & 3353 \\
\hline \multicolumn{3}{|l|}{ Digestible energy } \\
\hline Lactose (\%) & 8,64 & 8,64 \\
\hline \multicolumn{3}{|l|}{ Lactose } \\
\hline Cálcio (\%) & 0,82 & 0,82 \\
\hline \multicolumn{3}{|l|}{ Calcium } \\
\hline Fósforo disponível (\%) & 0,42 & 0,42 \\
\hline \multicolumn{3}{|l|}{ Available phosphorus } \\
\hline Sódio ( \%) & 0,24 & 0,24 \\
\hline \multicolumn{3}{|l|}{ Sodium } \\
\hline Metionina + cistina (\%) & 0,78 & 0,78 \\
\hline \multicolumn{3}{|l|}{ Methionine + cystine } \\
\hline Lisina (\%) & $1,20-1,50$ & $1,20-1,50$ \\
\hline \multicolumn{3}{|l|}{ Lysine } \\
\hline \multicolumn{3}{|c|}{ 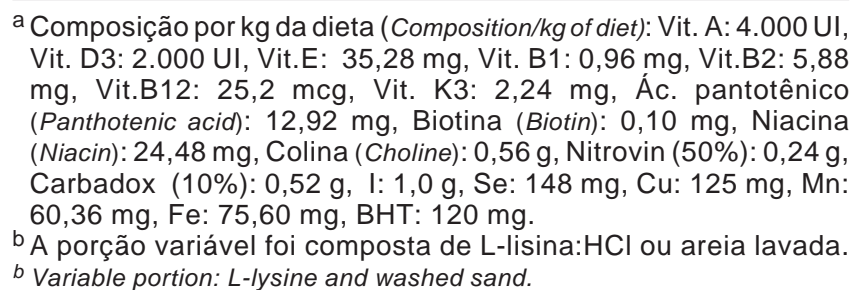 } \\
\hline
\end{tabular}

haver falta nem excesso, e as sobras foram retiradas sempre antes do arraçoamento seguinte.

As características zootécnicas avaliadas foram ganho de peso (kg), consumo de ração (kg) e índice de conversão alimentar. Procedeu-se à pesagem de todos 
Tabela 2 - Desempenho de leitões desmamados alimentados com diferentes fontes de lactose e níveis de lisina no período de 21 a 42 dias de idade

Table 2 - Performance of piglets fed different lactose sources and lysine levels from 21 to 42 days old

\begin{tabular}{|c|c|c|c|c|c|c|c|}
\hline \multirow[b]{2}{*}{$\begin{array}{l}\text { Parâmetro } \\
\text { Parameter }\end{array}$} & \multicolumn{2}{|c|}{$\begin{array}{l}\text { Peso desmame }(\mathrm{kg}) \\
\text { Weaning weight }\end{array}$} & \multicolumn{2}{|c|}{$\begin{array}{l}\text { Fonte de lactose } \\
\text { Lactose source }\end{array}$} & \multicolumn{2}{|c|}{$\begin{array}{l}\text { Nível de lisina (\%) } \\
\text { Lysine level }\end{array}$} & \multirow{2}{*}{$\begin{array}{l}\text { CV } \\
(\%)\end{array}$} \\
\hline & $\leq 6,0$ & $>6,0$ & $\begin{array}{l}\text { Soro leite } \\
\text { Dried whey }\end{array}$ & $\begin{array}{l}\text { Lactose } \\
\text { Lactose }\end{array}$ & 1,20 & 1,50 & \\
\hline $\begin{array}{l}\text { Ganho de peso }{ }^{1}, \mathrm{~kg} \\
\text { Weigth gain }\end{array}$ & 5,94 & 7,79 & 7,14 & 6,59 & 6,83 & 6,90 & 7,22 \\
\hline $\begin{array}{l}\text { Consumo }{ }^{2}, \mathrm{~kg} \\
\text { Feed intake }\end{array}$ & 11,51 & 14,15 & 12,94 & 12,71 & 12,89 & 12,76 & 8,37 \\
\hline $\begin{array}{l}\text { Conversão alimentar }{ }^{3}, \mathrm{~kg} / \mathrm{kg} \\
\text { Feed conversion }\end{array}$ & 1,95 a & $1,82 \mathrm{~b}$ & 1,83 & 1,94 & 1,90 & 1,86 & 6,99 \\
\hline
\end{tabular}

Médias para cada variável, seguidas da mesma letra em cada linha, não diferem $(P>0,05)$ pelo teste Tukey.

Means for each variable, followed by same letters, within a row, do not differ $(P>0.05)$ by Tukey test.

1,2 e 3 Interação significativa.

1,2 and 3 Significant interaction.

os animais no início (21 dias de idade) e no final do experimento (42 dias de idade), ocasião em que também foi realizado o controle do consumo das rações experimentais.

As características morfológicas avaliadas foram altura das vilosidades (HVILOS), profundidade das criptas (PCRIP) duodenais, bem como a relação HVILOS/PCRIP e relação peso do pâncreas/peso carcaça. Foram abatidos, aleatoriamente, ao final do período experimental, três animais por tratamento, para retirada e pesagem do pâncreas. Amostras de aproximadamente $1,0 \mathrm{~cm}$ de comprimento foram coletadas da porção proximal do duodeno de cada animal, sendo abertas em sua borda mesentérica, lavadas, estendidas pela túnica serosa e fixadas em solução de Bouin. O tempo despendido do abate ao início da fixação não ultrapassou cinco minutos. Depois de 24 horas na solução fixadora de Bouin, procedeu-se à lavagem das amostras em álcool etílico a $70^{\circ} \mathrm{GL}$ e, a seguir, à desidratação em séries crescentes de alcoóis. Posteriormente, estas amostras foram recortadas, diafanizadas em benzol e incluídas em parafina, de modo que se obtivessem cortes longitudinais da mucosa intestinal.

Em cada lâmina histológica, colocaram-se seis cortes semi-seriados com $5 \mathrm{~mm}$ de espessura, sendo desprezados seis entre um corte e o subseqüente. Prepararam-se três lâminas de cada animal e coraram-se os cortes segundo a técnica da hematoxilina de Harriseosina. Com as lâminas prontas, efetuaram-se 30 medidas de alturas das vilosidades (m) e 30 de profundidade das criptas $(\mathrm{mm})$ para cada segmento do duodeno coletado, o que possibilitou a obtenção da relação HVILOS x PCRIP do duodeno de cada animal.
As medidas de HVILOS foram tomadas a partir da região basal, que coincide com a porção superior das criptas, percorrendo-a longitudinalmente até seu ápice e as criptas, da sua base até a região de transição cripta-vilosidade.

Para a análise morfométrica, utilizou-se um sistema analisador de imagem da KONTRON ELEKTRONIK (Vídeo Plan) através de microscopia de luz, com um aumento de 230 vezes.

Para análise dos dados obtidos, empregou-se o programa ESTAT (Sistema de Análises Estatísticas), desenvolvido pelo Departamento de Ciências Exatas da UNESP/FCAVJ. As médias dos tratamentos foram comparadas pelo teste Tukey, a 5\% de probabilidade, segundo recomendações de Steel \& Torrie (1980).

\section{Resultados e Discussão}

Com base nos resultados médios de desempenho dos leitões apresentados nas Tabelas 2 e 3, verifica-se que o consumo de soro de leite em pó não apresentou diferenças no ganho de peso e na conversão alimentar para os níveis de lisina. No entanto, a inclusão de lactose na ração com $1,20 \%$ de lisina resultou em piores médias para conversão alimentar.

Verificou-se interação fonte de lactose $\times$ nível de lisina para ganho de peso e conversão alimentar (Tabela 3), obtendo-se as melhores médias de ganho de peso e conversão alimentar para o nível de 1,20\% de lisina, quando os leitões ingeriram ração contendo soro de leite em pó. Para o nível de 1,50\% de lisina, não houve influência da fonte de lactose sobre o ganho de peso e a conversão alimentar. 
Tabela 3 - Interação fonte de lactose $\times$ nível de lisina para ganho de peso e conversão alimentar de leitões desmamados, no período de 21 a 42 dias

Table 3 - Source lactose $\times$ lysine levels interaction for weight gain and feed conversion of piglets from 21 to 42 days old

\begin{tabular}{|c|c|c|c|c|}
\hline \multirow[t]{3}{*}{$\begin{array}{l}\text { Fonte de lactose }(\mathrm{kg}) \\
\text { Lactose source }\end{array}$} & \multicolumn{2}{|c|}{$\begin{array}{c}\text { Ganho de peso (kg) } \\
\text { Weigth gain }\end{array}$} & \multicolumn{2}{|c|}{$\begin{array}{l}\text { Conversão alimentar } \\
\text { Feed conversion }\end{array}$} \\
\hline & \multicolumn{2}{|c|}{$\begin{array}{l}\text { Nível de lisina (\%) } \\
\text { Lysine level (\%) }\end{array}$} & \multicolumn{2}{|c|}{$\begin{array}{l}\text { Nível de lisina (\%) } \\
\text { Lysine level (\%) }\end{array}$} \\
\hline & 1,20 & 1,50 & 1,20 & 1,50 \\
\hline $\begin{array}{l}\text { Soro de leite em pó } \\
\text { Dried whey }\end{array}$ & 7,32 Аа & 6,97 Aa & 1,79 Ab & $1,86 \mathrm{Aa}$ \\
\hline $\begin{array}{l}\text { Lactose } \\
\text { Lactose }\end{array}$ & $6,35 \mathrm{Ab}$ & 6,82 Аa & $2,02 \mathrm{Aa}$ & $1,87 \mathrm{Ba}$ \\
\hline
\end{tabular}

Médias seguidas da mesma letra minúscula em cada coluna e maiúscula em cada linha não diferem entre si pelo teste Tukey $(P>0,05)$

Means followed by the same letters, lower case in same column and upper case within a row do not differ (P>0.05) by Tukey test.

Registrou-se também interação peso ao desmame $\times$ nível de lisina para ganho de peso e consumo de ração (Tabela 4). Para os dois níveis de lisina (1,20 e $1,50 \%)$ nas rações, os leitões mais pesados apresentaram maiores médias tanto para ganho de peso quanto para consumo de ração. No entanto, dentro de cada peso ao desmame, não houve influência dos níveis de lisina sobre o ganho de peso e consumo de ração. Esses dados sugerem que o nível de 1,20\% de lisina satisfaz às exigências dos leitões, quando comparado ao nível de $1,50 \%$, independentemente do peso ao desmame.

Os resultados referentes às características duodenais e à relação peso de pâncreas x peso carcaça encontram-se na Tabela 5, em que os leitões com maior peso ao desmame apresentaram maior HVILOS $(\mathrm{P}<0,05)$ que os de menor peso. Neste caso, A profundidade média das criptas do duodeno foi influenciada somente pelo peso dos leitões ao desmame, demonstrando maiores valores $(\mathrm{P}<0,05)$ para os animais desmamados com peso maior que $6,0 \mathrm{~kg}$. Segundo Argenzio et al. (1990), o aumento na profundidade das criptas pode indicar aumento na atividade mitótica na cripta, em razão do estresse fisiológico (Argenzio et al., 1990). Entretanto, o desempenho apresentado pelos animais neste estudo demonstra que ocorreu adequada saúde intestinal capaz de permitir o crescimento adequado dos animais.

A relação HVILOS/PCRIP não apresentou diferença entre os diversos tratamentos estudados $(\mathrm{P}>0,05)$. A relação peso do pâncreas x peso corporal apresentou maiores valores para os leitões com menor peso ao desmame $(\leq 6,0 \mathrm{~kg})$, não sendo observada influência do tipo de dieta e dos níveis de lisina sobre esta variável.
As rações pós-desmame para leitões normalmente determinam o desempenho das fases posteriores, exigindo cuidados específicos em relação às características digestivas dos animais nesta fase. Assim, com a redução da idade ao desmame para menos de 30 dias, os leitões podem sofrer choques fisiológicos, mudanças físicas na mucosa intestinal, alterações na dieta e imaturidade imunológica, o que pode agravar os distúrbios digestivos (Robles, 1993; Whittemore, 1993). Portanto, fatores como idade ao desmame e composição das dietas fornecidas (Junqueira, 1991; Cole, 1997) devem ser considerados, porque interferem na capacidade digestiva e absortiva dos leitões.

Normalmente, essas situações são agravadas com o uso de dietas sólidas. Rostagno \& Pupa (1998) recomendam o uso de dietas líquidas para aumentar o consumo de ração pelos leitões após o desmame, como forma de estimulação do desenvolvimento digestivo, permitindo o aumento da digestibilidade dos nutrientes e a redução na incidência de problemas digestivos, em comparação a uma ração sólida. Destaca-se que Oliver et al. (2002), ao avaliarem a substituição da lactose por milho parcialmente hidrolizado, não verificaram diferenças sobre os parâmetros morfológicos intestinais de leitões desmamados aos 21 dias de idade.

Em revisão sobre o uso de produtos lácteos e suas alternativas em rações iniciais de suínos, Junqueira (1991) relatou que a composição da dieta em proteína, aminoácidos e outros nutrientes não determina o desempenho do animal, pois, se isso fosse verdadeiro, a simples incorporação de lisina, metionina, vitaminas e minerais corrigiria uma dieta à base de milho e farelo de soja. Robles (1993) ponderou que a identificação 
Tabela 4 - Interação peso ao desmame $\times$ nível de lisina para ganho de peso e consumo de ração de leitões desmamados, no período de 21 a 42 dias

Table 4 - Weaning weight $\times$ lysine levels interaction for weight gain and feed intake of piglets from 21 to 42 days

\begin{tabular}{|c|c|c|c|c|}
\hline \multirow[t]{3}{*}{$\begin{array}{l}\text { Pesos ao desmame }(\mathrm{kg}) \\
\text { Weaning weight }\end{array}$} & \multirow{2}{*}{\multicolumn{2}{|c|}{$\begin{array}{c}\text { Ganho de peso (kg) } \\
\text { Weigth gain } \\
\text { Nível de lisina (\%) } \\
\text { Lysine level (\%) }\end{array}$}} & \multirow{2}{*}{\multicolumn{2}{|c|}{$\begin{array}{l}\text { Consumo de ração } \\
\text { Feed intake }\end{array}$}} \\
\hline & & & & \\
\hline & 1,20 & 1,50 & 1,20 & 1,50 \\
\hline $\begin{array}{l}\leq 6,0 \\
>6,0\end{array}$ & $\begin{array}{l}5,69 \mathrm{Ab} \\
7,98 \mathrm{Aa}\end{array}$ & $\begin{array}{l}\text { 6,19 Ab } \\
7,60 \mathrm{Aa}\end{array}$ & $\begin{array}{l}11,09 \mathrm{Ab} \\
14,69 \mathrm{Aa}\end{array}$ & $\begin{array}{l}11,92 \mathrm{Ab} \\
13,60 \mathrm{Aa}\end{array}$ \\
\hline
\end{tabular}

Médias seguidas da mesma letra minúscula em cada coluna e maiúscula em cada linha não diferem $(P>0,05)$ pelo teste Tukey.

Means followed by the same letters, lower case in same column and upper case within a row do not differ (P>0.05) by Tukey test.

Tabela 5 - Morfologia intestinal do duodeno e relação peso do pâncreas/peso carcaça de leitões desmamados com diferentes pesos e alimentados com diferentes fontes de lactose e níveis de lisina

Table 5 - Intestinal morphology of duodenum and pancreas weight/carcass weight ratio of piglets with different weight and fed lactose sources and lysine levels

\begin{tabular}{|c|c|c|c|c|c|c|c|}
\hline \multirow[b]{2}{*}{$\begin{array}{l}\text { Parâmetro } \\
\text { Parameter }\end{array}$} & \multicolumn{2}{|c|}{$\begin{array}{l}\text { Peso desmame }(\mathrm{kg}) \\
\text { Weaning weight }\end{array}$} & \multicolumn{2}{|c|}{$\begin{array}{l}\text { Fonte de lactose } \\
\text { Lactose source }\end{array}$} & \multicolumn{2}{|c|}{$\begin{array}{c}\text { Nível de lisina (\%) } \\
\text { Lysine level }\end{array}$} & \multirow{2}{*}{$\begin{array}{l}\text { CV } \\
(\%)\end{array}$} \\
\hline & $\leq 6,0$ & $>6,0$ & $\begin{array}{l}\text { Soro leite } \\
\text { Dried whey }\end{array}$ & $\begin{array}{l}\text { Lactose } \\
\text { Lactose }\end{array}$ & 1,20 & 1,50 & \\
\hline $\begin{array}{l}\text { HVILOS }(\mathrm{mm})^{1} \\
\text { Villus height }\end{array}$ & $283 b$ & $328 \mathrm{a}$ & 305 & 305 & 308 & 303 & 15,43 \\
\hline $\begin{array}{l}\text { PCRIP }(\mathrm{mm}) \\
\text { Crypt depth }\end{array}$ & $113 \mathrm{a}$ & $135 b$ & $125 a$ & 123 a & 123 a & $125 \mathrm{a}$ & 16,04 \\
\hline $\begin{array}{l}\text { HVILOS/PCRIP } \\
\text { Villus height/Crypt depth }\end{array}$ & $2,42 \mathrm{a}$ & $2,50 \mathrm{a}$ & $2,44 \mathrm{a}$ & $2,48 \mathrm{a}$ & $2,50 \mathrm{a}$ & $2,43 \mathrm{a}$ & 4,07 \\
\hline $\begin{array}{l}\text { Pâncreas/carcaça (g/kg) } \\
\text { Pancreas/carcass }\end{array}$ & $2,34 \mathrm{a}$ & $2,02 \mathrm{~b}$ & $2,15 \mathrm{a}$ & $2,14 \mathrm{a}$ & $2,23 \mathrm{a}$ & $2,07 \mathrm{a}$ & 14,92 \\
\hline
\end{tabular}

Médias para cada variável, seguidas da mesma letra em cada linha, não diferem $(P>0,05)$ pelo teste Tukey.

Means for each variable, followed by the same letters, within a row, do not differ $(P>0.05)$ by Tukey test.

${ }^{1}$ Interação significativa.

1 Significant interaction.

dos melhores ingredientes para as dietas dos leitões desmamados deve ser prioridade em qualquer programa de alimentação, considerando-se o preço, a disponibilidade e o valor nutritivo dos alimentos.

Com relação à interação fonte de lactose $\times$ nível de lisina na ração observada para ganho de peso e conversão alimentar, a composição do soro de leite em pó, contendo lactose e também a sua proteína de origem láctea, provavelmente proporcionou diferença positiva na ração com 1,20\% de lisina. Mahan et al. (1993), estudando o uso de $20 \%$ de soro de leite em pó na ração de leitões, sugeriram que a lactose é o dissacarídeo mais limitante nas dietas à base de milho e farelo de soja, mas não observaram diferenças quando 8,8\% de lactose foi incluída nessas rações. Esse fato mostra que, ao contrário do sugerido, não é a lactose o único componente limitante em rações à base de milho e farelo de soja para leitões. Provavelmente, a associação de lactose e proteína de origem láctea no soro resultou em uma combinação mais equilibrada de nutrientes para os leitões, sob o ponto de vista digestivo. Tokach et al. (1990) demonstraram que os leitões apresentam melhor desempenho quando alimentados com rações contendo leite em pó e soro de leite, em comparação àquelas simples à base de milho e de farelo de soja.

Leitões desmamados com menor peso $(\leq 6,0 \mathrm{~kg})$ tiveram menor ganho de peso e menor consumo de 
ração que os desmamados com peso acima de 6,0 kg. Este resultado confirma as observações de Mahan \& Lepine (1991), ao verificarem que o menor peso dos leitões ao desmame foi determinante no desempenho nas fases subseqüentes. As respostas evidenciaram-se quando o desmame ocorreu entre 4,1 e $5,0 \mathrm{~kg}$, ao se compararem àquelas obtidas com leitões que começaram a fase inicial entre 5,5 e 6,8 ou 7,3 a 8,6 kg de peso.

A altura das vilosidades e a profundidade das criptas de Lieberkühn são afetadas diretamente pela qualidade dos ingredientes da ração na fase pósdesmame e, principalmente, pela quantidade de ração consumida (Lee et al., 2000; Mavromichalis et al., 2001). Dunsford et al. (1989) constataram que os melhores resultados para a digestibilidade dos nutrientes de rações contendo leite ou derivados lácteos devem-se ao equilíbrio da composição do leite pela presença da lactose e pelo perfil de aminoácidos em sua proteína. Pluske et al. (1996), em estudo de rações contendo leite de vaca, verificaram que a atividade enzimática e a capacidade de absorção de nutrientes foram influenciadas pelos parâmetros morfométricos. O ingrediente favoreceu o desempenho dos leitões em relação aos alimentados com rações formuladas apenas à base de proteína da soja.

Hampson (1986), em comparação de leitões desmamados e lactentes de mesmas idades, observou que os desmamados apresentaram alterações significativas na morfologia intestinal, com redução na altura das vilosidades e aumento da profundidade das criptas. Isso resultou em redução da capacidade absortiva do intestino delgado, predispondo a distúrbios digestivos muito comuns nesta fase, como o aumento da ocorrência de diarréias.

Segundo Cline (1992), a evolução fisiológica do trato gastrointestinal do leitão está estreitamente ligada às condições e ao tipo de ingredientes utilizados na ração. Com o desmame, o desenvolvimento da capacidade digestiva e absortiva do animal passa de uma condição de excelente aproveitamento dos nutrientes contidos no leite para uma rápida adaptação à digestão de alimentos sólidos, o que ocorre principalmente com a combinação de lactose e proteínas de origem animal na dieta inicial.

Makkink et al. (1994) verificaram que a relação peso do pâncreas x peso corporal foi de 1,53 e 1,27 g/kg para leitões abatidos aos três dias após o desmame, quando receberam na ração leite em pó e farelo de soja, respectivamente, observando que o farelo de soja apresentou valores significativamente menores, que desapareceram após o sexto dia. Anteriormente, Rioperez et al. (1993) registraram que o peso do pâncreas de leitões de 35 dias de idade não foi influenciado pelas rações pós-desmame contendo soja processada de diferentes formas (tostada, extrusada e micronizada) em substituição ao leite em pó.

\section{Conclusões}

O uso de lactose em rações à base de milho e farelo de soja proporcionou melhor desempenho dos leitões, quando combinado ao nível de 1,50\% de lisina, independentemente do peso ao desmame. Além disso, foi observado que a altura das vilosidades do duodeno é uma função direta do peso do leitão ao desmame e independente do fornecimento de dietas contendo de soro de leite ou lactose.

\section{Literatura Citada}

ARGENZIO, R.A.; LIACOS, J.A.; LEVY, M.L. et al. Villous atrophy, crypt hyperplasia, cellular infiltration, and impaired glucosa-Na absorption in enteric cryptosporidiosis of pigs. Gastroenterology, v.98, n.8, 1129-1140, 1990.

BAKER, D.H. Nutrient allowances for swine. Feedstuffs, v.35, p.40-44, 1998.

CLINE, T.R. Development of the digestive physiology of baby pigs and the use of supplemental enzimes in their diets. In: SIMPÓSIO DO COLÉGIO BRASILEIRO DE NUTRIÇÃO ANIMAL, 1992, Campinas. Anais... Campinas: Colégio Brasileiro de Nutrição Animal, 1992. p.149-161.

COLE, D.J.A. Combining the benefits of ultimate protein 1672 with the concept of na ideal protein. In: BIOTECHNOLOGY IN THE FEED INDUSTRY ALLTECH'S ANNUAL SYMPOSIUM, 1997, Nicholasville. Proceedings... Thrumpton: Nottingham University Press, 1997. p.327-335.

DANIELSON, D.M.; PEO, E.R.; HUDMAN, D.B. Ratios of dried skim milk and dried whey for pigs starter rations. Journal of Animal Science, v.19, n.11, p.1055-1061, 1960. DONZELE, J.L.; COSTA, P.M.A.; ROSTAGNO, H.S. et al. Níveis de lisina para suínos de 5 a 15 kg. Revista Brasileira de Zootecnia, v.21, n.9, p.1084-1090, 1992.

DUNSFORD, B.R.; KNABE, D.A.; HAENSLY, W.E. Effect of dietary soybean meal on the microscopic anatomy of the small intestine in the early weaned pig. Journal of Animal Science, v.67, n.12, p.1855-1863, 1989.

ETHERIDGE, R.D.; SEERLEY, R.W.; WYATT, R.D. The effect of diet on performance, digestibility, blood composition and intestinal microflora of weaned pigs. Journal of Animal Science, v.58, n.9, p.1396-1402, 1984.

HAMPSON, D.J.; KIDDER, D.E. Influence of creep feeding and weaning on brush border enzyme activities in the piglet small intestine. Research Veterinary Science, v.40, n.1, p.24-31, 1986.

JUNQUEIRA, O.M. Alternativas para produtos lácteos em rações iniciais para suínos. In: MINI-SIMPÓSIO DO COLÉ- 
GIO BRASILEIRODE NUTRIÇÃO ANIMAL, 1991, Campinas. Anais... Campinas: Colégio Brasileiro de Nutrição Animal, 1991. p.53-70.

KENWORTHY, R. Observation of the effects of weaning in the young pig. Clinical and histopathological studies of intestinal function and morphology. Research Veterinary Science, v.21, n.1, p.69-73, 1976.

LEE, C.H.; HAN, Y.K.; LEE, K.U. et al. Study on the nutritive value of dextrin as a carbohydrate source for pigs weaned at 21 days of age. Journal of Animal and Feed Science, v.9, n.3, p.647-663, 2000.

LEPINE, A.J.; MAHAN, D.C., CHUNG, Y.K. Growth performance of weanling pigs fed corn-soybean meal diets with or without dried whey at various L-Lysine-HCl levels. Journal of Animal Science, v.69, n.12, p.2026-2032, 1991.

MAHAN, D.C.; EASTER, R.A.; CROMWELL, G.L. et al. Effect of dietary lysine levels formulated by altering the ratio of corn:soybean meal with or without dried whey and L-lysine. $\mathrm{HCl}$ in diets for weanling pigs. Journal of Animal Science, v.71, n.10, p.1848-1852, 1993.

MAHAN, D.C.; LEPINE, A.J. Effect of pig weaning weight and associated nursery feeding programs on subsequent performance to 105 kilograms body weight. Journal of Animal Science, v.69, n.6, p.1370-1378, 1991.

MAKKINK, C.A.; STUART, J.N.; HILL, W.C. et al. Effect of dietary protein source on feed intake, growth, pancreatic enzyme activities and jejunal morphology in newlyweaned piglets. British Journal Nutrition, v.72, n.2, p.353-68, 1994.

MAVROMICHALIS, I.; HANCOCK, J.D.; HINES, R.H. et al. Lactose, sucrose and molasses in simple and complex diets for nursery pigs. Animal Feed Science and Technology, v.93, n.1, p.127-135, 2001.

MILLER, B.G.; WHITTEMORE, C.T.; STOKES, C.R. et al. Effect of weaning on the capacity of pigs intestinal villi to digest and absorb nutrients. Journal Agriculture Science, v.107, n.3, p.579-589,1986.

MILLER, B.G.; NEWBY, T.J., STOKES, C.R. et al. The importance of dietary antigen in the cause of postweaning diarrhea in pigs. American Journal Veterinay Research, v.45, n.9, p.1730-1733, 1984.

NABUURS, M.J.A. Morphological, structural and functional changes of the small intestine of pigs at weaning. Pig News Information, v.16, n.3, p.93N-97N, 1995.

NATIONAL RESEARCH COUNCIL - NRC. Nutrient requirements of swine. 10.ed. Washington, D.C.: National Academy of Science, 1998. 189p.

OLIVER, W.T.; MATHEWS, S.A.; PHILLIPS, O. et al. Efficacy of partially hydrolyzed corn syrup solids as a replacement for lactose in manufactured liquid diets for neonatal pigs. Journal of Animal Science, v.80, n.1, p.143-153, 2002

PARTRIDGE, I. Atualização dos conceitos europeus de alimentação para leitões e marrãs. In: SIMPÓSIO DE COLÉGIO BRASILEIRO DE NUTRIÇÃO ANIMAL, 1988, Campinas. Anais... Campinas: Colégio Brasileiro de Nutrição Animal, 1988. p.19-40.
PASSILlÉ, A.M.B.; PELLETIER, G.; MÉNARD, J. et al. Relationships of weight gain and behavior to digestive organ weight and enzyme activities in piglets. Journal of Animal Science, v.67, n.12, p.2921-2929, 1989.

PEKAS, J.C.; HAYS, V.W.; THOMPSON, A.M. Exclusion of the exocrine pancreatic secretion: Effect on digestibility of soybean and milk protein by baby pigs at various ages. Journal of Nutrition, v.82, n.2, p.277-306, 1964.

PLUSKE, J.R.; WILLIAMS, I.H.; AHERNE, F.X. Villous height and crypt depth in piglets in response to increases in the intake of cows' milk after weaning. Animal Science, v.62, n.1, p.145-158, 1996.

RIOPEREZ, J.; SALANOVA, H.; COSTA, J.S. et al. Efecto de la alimentación com harina de soja sometida a distintos tratamientos sobre el crecimiento y morfologia intestinal del lechón. Archivos Zootecnia, v.42, n.1, p.12535, 1993.

ROBLES, A. Alimentación del lechon. In: MINI-SIMPÓSIO DO COLÉGIO BRASILEIRO DE NUTRIÇÃO ANIMAL, 1993, Valinhos. Anais... Campinas: Colégio Brasileiro de Nutrição Animal, 1993. p.83-100.

ROSTAGNO, H.S.; SILVA, D.J.; COSTA, P.M.A. et al. Composição de alimentos e exigências nutricionais de aves e suínos (tabelas brasileiras). Viçosa, MG: Universidade Federal de Viçosa, 1994. 59p.

ROSTAGNO, H.S.; PUPA, J.M.R. Fisiologia da digestão e alimentação dos leitões. In: SIMPÓSIO SOBRE NUTRIÇÃO E MANEJO DE LEITÕES, 1998, Campinas. Anais... Campinas: Colégio Brasileiro de Nutrição Animal, 1998. p. 60-87.

STEEL, R.G.D.; TORRIE, J.H. Principles and procedures of statistics. New York: McGraw-Hill Book Company, 1980. 633p.

TOKACH, M.D.; PETTIGREW, J.E.; JOHNSON, L.J. et al. Overall pig performance to market weight is improved by adding milk products, but not fat, to the starter diet. Journal of Animal Science, v.68, Suppl.1, p.377-378, 1990.

SPREEUWENBERG, M.A.M.; VERDONK, J.M.A.J.; VERSTEGEN, M.W.A. et al. Villus height and gut development in weaned piglets receiving diets containing either glucose, lactose or starch. British Journal of Nutrition, v.90, n.4, p.907-913, 2003.

VERDONK, J.M.A.J.; SPREEUWENBERG, M.A.M.; BAKKER, G.C.M. et al. Nutrient intake level affects histology and permeability of the small intestine in newly weaned piglets. In: CABI (Ed.) Digestive physiology of pigs. Wallingford: CABI Publishing, 2001. p.332-334

WALKER, W.R.; MAXWELL, C.V.; OWENS, F.N. et al. Milk versus soybean protein sources for pigs: Effects on performance and digestibility. Journal of Animal Science, v.63, n.2, p.505-512, 1986.

WHITTEMORE, C. The science and practice of pig production. Essex: Longman Scientific \& Technical, 1993. p.304-321.

Recebido em: 06/10/03 Aceito em: 07/07/05 